\title{
Pyoderma Gangrenosum Masquerading as Necrotizing Fasciitis: Stepping Away from Cognitive Shortcuts
}

\author{
Rachael Hilton $^{1,2}$, Jefferson Berryman ${ }^{1,3}$, Karina Handoyo ${ }^{1,4}$ \\ ${ }^{1}$ Presbyterian/St. Luke's Medical Center, Denver, CO, USA \\ ${ }^{2}$ Medical University of South Carolina, Charleston, SC, USA \\ ${ }^{3}$ University of California, Davis, Davis, CA, USA \\ ${ }^{4}$ University of Colorado Hospital, Aurora, CO, USA
}

Received: 01/06/2017

Accepted: $19 / 06 / 2017$

Published: 07/07/2017

How to cite this article: Hilton R, Berryman J, Handoyo K. Pyoderma gangrenosum masquerading as necrotizing fasciitis: stepping away from cognitive shortcuts. EJCRIM 2017;4: doi:10.12890/2017_000648.

Conflicts of Interests: The Authors declare that there are no competing interests.

This article is licensed under a Commons Attribution Non-Commercial 4.0 License

\section{ABSTRACT}

A patient with post-Cesarean wound complication was treated for necrotizing fasciitis (NF) with sharp debridement and broad-spectrum antibiotics. Several operations and three weeks later, her abdominal skin, subcutaneous fat, right-sided rectus abdominus, and underlying fascia had been removed without any improvement in granulation tissue. Original pathology samples demonstrated sheets of necrosis consistent with NF, but were re-reviewed by a dermatopathologist who diagnosed the patient with pyoderma gangrenosum (PG). She was started on high-dose steroids and dapsone, and her wound quickly showed signs of improvement. Anchor bias delayed the initiation of steroids and diagnosis of PG as the surgical, medical, and consulting teams were hesitant to stray from the diagnosis of NF.

\section{LEARNING POINTS}

- Pyoderma gangrenosum is often confused with other dermatological disorders in the hospital setting.

- It is vital to recognize the tendency towards anchoring bias, and how this can greatly affect our patient care.

\section{KEYWORDS}

Pyoderma gangrenosum, necrotizing fasciitis, anchoring bias

\section{CASE DESCRIPTION}

A 28-year-old G1P1 healthy woman was admitted 7 days after caesarean section. On admission, she met sepsis criteria with leukocytosis, a temperature of $38.9^{\circ} \mathrm{C}$ and tachycardia. Her scar was tender and erythematous with surrounding purple discoloration. Within a few hours, the edges of her scar had turned dusky, extending well outside the original borders. Aggressive debridement of the wound followed and broad-spectrum antibiotics were started as a diagnosis of necrotizing fasciitis (NF) was made. Hospitalist and infectious disease services were consulted for medical management. 


\section{METHODS AND PROCEDURES}

During the following weeks, the patient underwent multiple surgeries and treatment with hyperbaric oxygen therapy. Surgical specimens were read as 'sheets of necrosis consistent with NF', and wound cultures initially were positive but persistently negative thereafter. Despite this, the patient's condition worsened, with the wound growing to encompass the entire abdomen and necrosis spreading to the right-sided rectus abdominis and peritoneum. During hospitalization, the patient developed acute blood loss anaemia requiring 13 pRBC transfusions, an acute kidney injury secondary to fluid losses, anasarca from overhydration and third spacing, a left upper extremity deep vein thrombosis associated with the PICC line, elevated liver enzymes related to sepsis and antibiotic side effects, and depression. Only after 10 surgical debridements without improvement did additional history obtained by the medical team reveal that her grandmother had had pyoderma gangrenosum (PG) with a similar presentation. A dermatopathologist was asked by the hospitalist service to re-evaluate the surgical biopsies, and determined they were more consistent with PG given the clinical history and lack of microscopic bacteria.

A regimen of $1 \mathrm{~g}$ intravenous (IV) methylprednisone daily was given for the first 3 days along with $100 \mathrm{mg}$ oral dapsone daily. This was followed by $100 \mathrm{mg}$ oral prednisone and dapsone daily. The patient's vital signs quickly improved and the wound stopped progressing, although it took over a week before new granulation tissue started to grow (Fig. 1). During the steroid taper and healing process, mesh was placed over the patient's small intestine on the right side, as the rectus abdominis and peritoneum had been removed due to necrosis. Unavoidable erosion from the mesh led to an enterocutaneous fistula, but this was repaired following weeks of bowel rest and continued granulation tissue growth. After a couple weeks of healing, a cadaver skin graft was placed over the area. A week later, while still on a steroid taper, the upper edges of the patient's abdominal wound turned reddish-purple and a recurrence of PG was diagnosed. Her steroids were increased again and dapsone was restarted which stopped the inflammatory process. Forty days later a permanent skin graft was placed and the patient was discharged on a low-dose steroid taper with future plans to discontinue all immunosuppressants (Fig. 2).

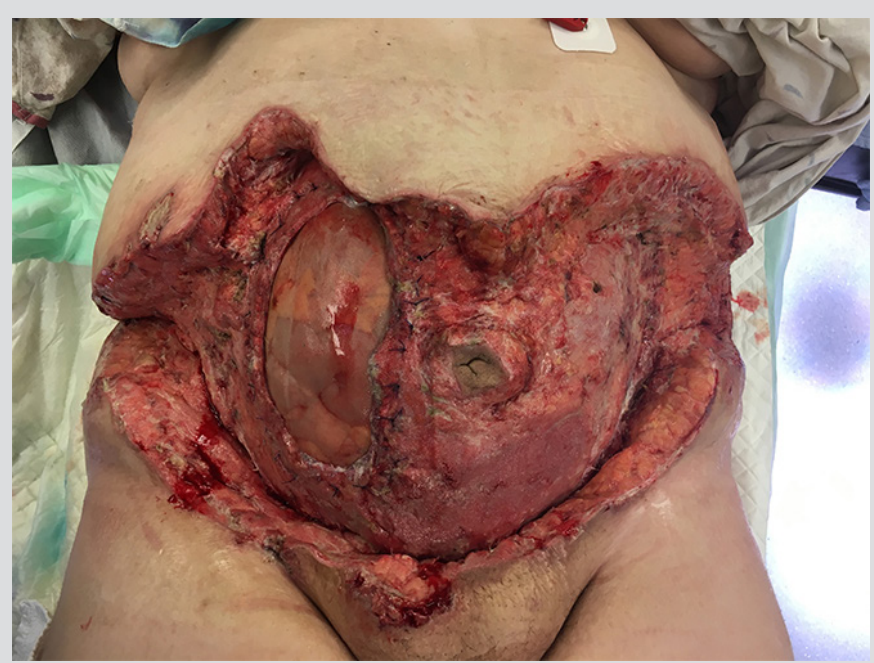

Figure 1. Abdominal wound 1 week after initiation of steroids and first mesh placement.

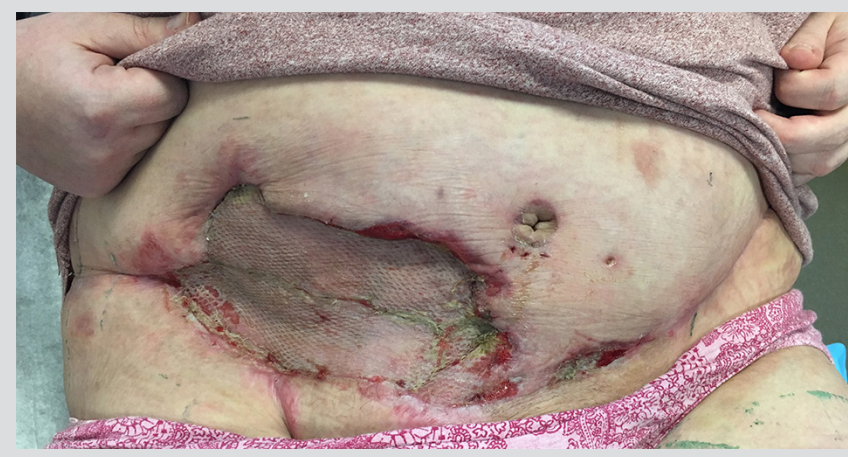

Figure 2. Abdomen 1 week after autologous skin graft placement.

\section{DISCUSSION}

Pyoderma gangrenosum is a skin condition characterized by intense inflammation, which can certainly be mistaken for infection. It is a rare and often recurring chronic neutrophilic dermatosis, which predominantly occurs on the lower extremities in patients with inflammatory and haematological disorders ${ }^{[1]}$. Originally thought to be caused by bacteria of the genus Streptococcus, PG is now considered an autoimmune disease. Pathergy (wound exaggeration following minor trauma) is the inciting factor in most cases of $\mathrm{PG}^{[2]}$. The classic form of PG is characterized by inflamed and violaceous, undermined edges surrounding a central ulcer causing severe pain ${ }^{[3]}$. The disease lacks specific clinical and histological findings, and diagnosis rests upon elimination of other conditions. Infections, malignancies, vascular diseases and anthrax must be included in the differential diagnosis ${ }^{[2]}$. High-dose IV corticosteroids are first-line treatment, but cyclosporine and dapsone 
are often added ${ }^{[3]}$. Recent studies show cyclosporine alone has similar rates of healing compared to steroids, but cyclosporine usage is often limited by kidney function ${ }^{[4]}$. There are case reports of azathioprine, cyclophosphamide, tacrolimus, mercaptopurine, sulphasalazine, sulphapyridine, thalidomide, clofazimine, isotretinoin, and plasmapharesis being used for PG ${ }^{[2,3,4]}$.

Review of the literature reveals several mentions of post-operative PG being mistaken for NF. Most cases involve the breast or an extremity, but there are a few isolated cases of PG after caesarean section. Table 1 lists reported cases of PG following caesarean section, with the average time to development being 4-5 days after surgery. The primary treatment used was overwhelmingly corticosteroids, but cyclosporine and dapsone were employed in several cases. Surgical intervention involved wound care and/or skin grafting once granulation tissue was present.

Our case illustrates the difficulty of diagnosing PG and the importance of re-evaluating an existing diagnosis. Our patient had no predisposing conditions for PG, other than a family history, which was only revealed weeks after admission. None of the wounds in the cases found in the literature were as extensive as in our patient, which involved the subcutaneous tissue, rectus abdominis and peritoneum. The pathology sections from initial debridement were read as 'sheets of necrosis consistent with NF', and unfortunately PG and NF are treated in completely different ways. NF requires rapid and aggressive debridement along with broad-spectrum antibiotics, whereas PG drastically worsens with surgery and requires immunosuppression to halt the inflammatory response ${ }^{[5]}$. Even though our patient's wound worsened with debridement, consulting teams resisted alternative diagnoses for several weeks.

It is human nature to form a judgment based on first clinical and pathological impressions. In medicine, this tendency to make clinical decisions heavily based on the first piece of information is called anchoring bias. In hospital medicine, anchoring often happens in cases considered 'typical'. Readily available diagnoses are at the forefront of our brains, often limiting the consideration of broad differentials through availability bias, thus leaving out uncommon diagnoses. Confirmation bias occurs after one forms an opinion and proceeds to only notice facts in support of this opinion while ignoring contrary evidence. Although these cognitive shortcuts can help physicians become more efficient clinical decision makers, they can lead to significant error. PG is an uncommonly encountered disease for hospitalists and general pathologists, which made it easy to anchor to the readily available diagnosis of NF in this case. When classic cases start to deviate from their usual course, it is important to step away from our cognitive shortcuts and reconsider all the possible diagnoses.

\section{REFERENCES}

1. De Souza EFA, da Silva GAR, dos Santos GR, Motta HL de SN, Cardoso PANM, de Azevedo MCVM, et al. Pyoderma gangrenosum simulating necrotizing fasciitis. Case Rep Med 2015;2015:504970.

2. Cozzani E, Gasparini G, Parodi A. Pyoderma gangrenosum: a systematic review. G Ital Dermatol Venereol 2014;149:587-600.

3. Patel F, Fitzmaurice S, Duong, C, He Y, Fergus J, Raychaudhuri S, et al. Effective strategies for the management of pyoderma gangrenosum: a comprehensive review. Acta Derm Venereol 2015;95:525-531.

4. Ormerod AD, Thomas KS, Craig FE, Mitchell E, Greenlaw N, Norrie J, et al. Comparison of the two most commonly used treatments for pyoderma gangrenosum: results of the STOP GAP randomised controlled trial. BMJ 2015;350:h2958.

5. Bisarya K, Azzopardi S, Lye G, Drew PJ. Necrotizing fasciitis versus pyoderma gangrenosum: securing the correct diagnosis! A case report and literature review. Eplasty 2011;11:e24.

6. Shands JW, Flowers FP, Hill HM, Smith O. Pyoderma gangrenosum in a kindred. J Am Acad Dermatol 1987;16:931-934.

7. Harland CC, Jaffe W, Holden CA, Ross LD. Pyoderma gangrenosum complicating caesarian section. J Obstet Gynaecol 1993;13:115-116.

8. Stone N, Harland C, Ross L, Holden C. Pyoderma gangrenosum complicating caesarian section. Clin Exp Dermatol 1996;21:468.

9. Steadman UA, Brennan TE, Daman LA, Curry SL. Pyoderma gangrenosum following caesarean delivery. Obstet Gynecol 1998;91:834-836.

10. Rönnau AC, Schmiedeberg S, Bielfeld P, Ruzicka T, Schuppe HC. Pyoderma gangrenosum after caesarean delivery. Am J Obstet Gynecol 2000;183:502-504.

11. Amin SV, Bajapai N, Pai A, Bharatnur S, Hebbar S. Pyoderma gangrenosum in two successive pregnancies complicating caesarean wound. Case Rep Obstet Gynecol 2014;2014:13.

12. Karim AA, Ahmed N, Salman TA, Craven NM. Pyoderma gangrenosum in pregnancy. J Obstet Gynaecol 2006;26:463-466.

13. Banga F, Schuitemaker N, Meijer P. Pyoderma gangrenosum after caesarean section: a case report. Reprod Health 2006;22:1-5.

14. Sanz-Muñoz C, Martinez-Moran C, Miranda-Romero A. Pyoderma gangrenosum following cesarean delivery. Actas Dermo-Sifiliográficas 2008;99:477-480.

15. Pauser S, Goerge T, Eickelmann M, Gaubitz M, Luger TA, Steinhoff M. Pyoderma gangrenosum after cesarean delivery. Clin Med Insights Dermatol $2009 ; 2: 23$.

16. Park JY, Lee J, Park JS, Jun JK. Successful vaginal birth after prior cesarean section in a patient with pyoderma gangrenosum. Obstet Gynecol Sci 2016;59:62-65.

17. Radhika A, Singal A, Radhakrishnan G, Singh S. Pyoderma gangrenosum following a routine caesarean section: pseudo-infection in a caesarean wound. Qatar Med J 2015;2015:1.

18. Aydın S, Aydın ÇA, Uğurlucan FG, Yaşa C, Dural Ö. Recurrent pyoderma gangrenosum after cesarean delivery successfully treated with vacuum-assisted closure and split thickness skin graft: a case report. J Obstet Gynaecol Res 2014;41:635-639.

19. Nonaka T, Yoshida K, Yamaguchi M, Aizawa A, Fujiwara H, Enomoto T, Takakuwa K. Case with pyoderma gangrenosum abruptly emerging around the wound of cesarean section for placenta previa with placenta accrete. J Obstet Gynaecol Res 2016;42:1190-1193. 


\begin{tabular}{|c|c|c|c|c|}
\hline Case report & Date & Risk factors & Location(s) & Treatment \\
\hline Shands et al. ${ }^{[6]}$ & 1987 & Family history & Abdomen & Steroids \\
\hline Harland et al. ${ }^{[7]}$ & 1993 & None & Abdomen & Steroids+surgery \\
\hline Stone et al. ${ }^{[8]}$ & 1996 & None & Abdomen & Steroids+surgery \\
\hline Steadman et al. ${ }^{\left[{ }^{[9]}\right.}$ & 1998 & Hypogammag-lobulinaemia & Abdomen & Steroids \\
\hline Rönnau et al. ${ }^{110]}$ & 2000 & Hepatitis C virus & Abdomen & Steroids+cyclosporine \\
\hline Amin et al. ${ }^{[11]}$ & $\begin{array}{l}2005 \\
\text { Recurrence } 2014\end{array}$ & N/A & $\begin{array}{l}\text { Abdomen }+ \text { leg } \\
\text { Abdomen }\end{array}$ & $\begin{array}{l}\text { Dapsone } \\
\text { Steroids+dapsone }\end{array}$ \\
\hline Karim et al. ${ }^{[12]}$ & 2006 & Family history & Abdomen & Steroids \\
\hline Banga et al. ${ }^{[13]}$ & 2006 & None & Abdomen & Steroids \\
\hline Sanz-Muñoz et al. ${ }^{[14]}$ & 2007 & None & Abdomen+leg & Topical steroids \\
\hline Pauser et al. ${ }^{[15]}$ & 2009 & None & Abdomen & Steroids+cyclosporine \\
\hline Park et al. $\left.{ }^{16]}\right]$ & 2011 & None & Abdomen & Steroids+cyclosporine+dapsone \\
\hline Radhika et al. ${ }^{[17]}$ & 2013 & None & Abdomen & Steroids+cyclosporine+dapsone \\
\hline Aydin et al. ${ }^{[18]}$ & 2014 & None & Abdomen & Steroids+azathioprine+surgery \\
\hline Nonaka et al. ${ }^{[19]}$ & 2016 & None & Abdomen & Steroids \\
\hline Our case & $\begin{array}{l}2016 \\
\text { Recurrence } 2017\end{array}$ & Family history & $\begin{array}{l}\text { Abdomen } \\
\text { Abdomen }\end{array}$ & $\begin{array}{l}\text { Surgery } \\
\text { Steroids+dapsone+ surgery }\end{array}$ \\
\hline
\end{tabular}

